Proceedings

\title{
Impact of Brushing and Infill Maintenance on Field Safety of Third Generation Synthetic Turf ${ }^{+}$
}

\author{
Kyley Dickson 1,*, John Sorochan ${ }^{1}$, William Strunk ${ }^{2}$ and Taylor Williams ${ }^{1}$ \\ 1 Plant Science Department, University of Tennessee, Knoxville, TN 37996, USA; sorochan@utk.edu (J.S.); \\ twill117@utk.edu (T.W.) \\ 2 Agriculture and Food Science Department, Western Kentucky University, Bowling Green, KY 42101, USA; \\ william.strunk@wku.edu \\ * Correspondence: kdickso1@utk.edu; Tel.: +1-931-397-1385 \\ + Presented at the 13th conference of the International Sports Engineering Association, Online, 22-26 June 2020.
}

Published: 15 June 2020

\begin{abstract}
The objective of this study was to investigate the impact of brushing and infill maintenance of third generation (3G) synthetic turf on field safety. A split-plot randomized complete block design was used with six different fiber pile heights, infill depths, and shock pad combinations subjected to 120 games in the summer of 2017 at the Center for Athletic Field Safety (CAFS) in Knoxville, TN, USA. Traffic was applied with a CAFS traffic simulator. Half of the plots received maintenance every 20 games with a rotating power broom and infill applied to those below manufacturer's recommendations. All 3G synthetic turf systems required maintenance to the same degree, and maintenance was necessary to keep surface hardness of 3G synthetic turf systems consistent and acceptable. Overall, field safety and consistency increased in this study due to maintenance, thus suggesting brushing and infill maintenance plays a vital role in maintaining high performance on 3G synthetic fields.
\end{abstract}

Keywords: synthetic turf; maintenance; infill; shock pads

\section{Introduction}

Currently, there are more than 6000 synthetic fields in the U.S. [1]. The use of synthetic fields has grown greatly since their inception in 1966 and they are now found worldwide. Most synthetic turf fields come with a warranty that is contingent upon regular maintenance [1]. One study found that due to high usage, limited maintenance and lack of field control at installation could lower the lifespan of a third generation (3G) synthetic field to less than five years [2]. While another study found that a poor maintenance program could reduce the lifespan of a 3G turf pitch by three years [3].

Compaction, while a common problem on natural grass fields, has been found to be a problem on 3G synthetic turf infills [4]. The increases in compaction resulted in higher surface hardness values and increased infill bulk densities [4]. A conceptual model formulated that foreign debris, mechanical wear, and weather impact system components of permeability, hardness, friction, and carpet wear [5]. Regular maintenance was shown to increase surface regularity, shock absorption, vertical deformation, and reduce ball roll distance [3]. The importance of 3G turf maintenance is critical due to its impact on many factors of a field/pitch [2-5].

While previous research has focused on metal rakes/spikes pulled across a surface, few studies have investigated the impact of brushing. This study looks to explore the benefits of brushing and infill depth maintenance on field performance. The objective of this study is to determine the impact of brushing and infill maintenance of synthetic turf on field safety and consistency of different turf 
systems. The authors' hypothesis is that brushing and infill maintenance will provide a more consistent surface and increase field safety.

\section{Materials and Methods}

In 2017, a study was conducted at the University of Tennessee Center for Athletic Field Safety (Knoxville, TN, USA) to determine the impact of brushing and infill maintenance of a 3G synthetic turf on field safety. A split-plot randomized complete block design was used with six different treatment systems consisting of different pile density, pile heights, infill depths, and shock pad combinations subjected to 120 games. The whole plot comprised the 3G synthetic turf system subjected to traffic. The sub-plot was the application of maintenance or no maintenance. The six $3 \mathrm{G}$ synthetic system treatments are described in Table 1 . The treatments will be discussed in the results by the treatment number as defined in Table 1 . The treatments are representative of the commonly found variety of $3 \mathrm{G}$ synthetic American football fields. All plots were constructed over a gravel base.

Table 1. Third generation (3G) synthetic turf treatment combination description.

\begin{tabular}{cccc}
\hline $\begin{array}{c}\text { Treatment } \\
\text { Number }\end{array}$ & $\begin{array}{c}\text { 3G Synthetic Turf } \\
\text { (Pile Density; Pile Height) }\end{array}$ & Infill & Shock Pad \\
\hline 1 & $1.47 \mathrm{~kg} / \mathrm{m}^{2} ; 50 \mathrm{~mm}$ pile height & Crumb Rubber & Extruded Rubber \\
\hline 2 & $1.47 \mathrm{~kg} / \mathrm{m}^{2} ; 50 \mathrm{~mm}$ pile height & Crumb Rubber & Beaded Polypropylene \\
\hline 3 & $1.47 \mathrm{~kg} / \mathrm{m}^{2} ; 38 \mathrm{~mm}$ pile height & Coconut/Cork & Extruded Rubber \\
\hline 4 & $1.47 \mathrm{~kg} / \mathrm{m}^{2} ; 38 \mathrm{~mm}$ pile height & Recycled Rubber & Extruded Rubber \\
\hline 5 & $2.27 \mathrm{~kg} / \mathrm{m}^{2} ; 32 \mathrm{~mm}$ pile height & Coconut/Cork & Beaded Polypropylene \\
\hline 6 & $0.85 \mathrm{~kg} / \mathrm{m}^{2} ; 64 \mathrm{~mm}$ pile height & Crumb Rubber & None \\
\hline
\end{tabular}

Whole plots were 4.5 by $9 \mathrm{~m}$ with the sub-plot being 1.5 by $4.5 \mathrm{~m}$. Each plot and sub-plot were replicated three times throughout the study. Traffic was applied using a Center for Athletic Field Safety (CAFS) traffic simulator at a rate of 10 games (simulated football games) per week until 120 games were achieved [6]. If infill dropped below $10 \%$ of the original install after 20 games, infill was added and maintenance was completed with a rotating power broom (Toro Power Broom, Toro, Bloomington, MN, USA). The period of every 20 games was selected to correspond with local high school grooming protocols.

Data were collected before traffic initiation and after every 20 games after maintenance application through to the end of the study. Five different types of tests were collected: surface hardness, head injury criterion, infill depth, fiber reveal, and fiber weight. Surface hardness was collected using the F355-A missile following ASTM standard at three locations per sub-plot [7]. An F355-E testing device was used to quantify head injury criterion (HIC) [8]. The HIC values were collected from a $1.3 \mathrm{~m}$ height at nine locations per sub-plot. The HIC critical threshold of 1000 was established as the critical limit for this study, corresponding with the ASTM standard [8].

Infill depth was collected at nine locations per sub-plot using a digital handheld infill depth gauge with three prongs (Canadian Playground Advisory Digital Infill Depth Gauge, Canadian Playground Advisory, Inc, Cambridge, ON, USA). Fiber reveal data were collected using a prism gauge at six locations per sub-plot (Turf-Tec Grass Height Prism Gauge, Turf-Tech Int., Tallahassee, FL, USA). In addition, a 5 by $5 \mathrm{~cm}$ area of turf had all fibers removed and weighed prior to and after conclusion of the study for all plots to determine pile weight. Analyses of variance were conducted in SAS (v. 9.3; SAS Institute Inc., Cary, NC, USA). Data from this study were analyzed as a split-plot randomized complete block design in SAS ( $v$ 9.4). Comparison of means and the interaction of means were considered significant at $\alpha=0.05$. Model parameter estimates and correlations were calculated in GraphPad Prism 6. 


\section{Results}

Surface hardness was significantly different for each system due to the inherent system properties across all games, as shown in Table 2 and Figure 1. Maintenance had a significant effect on surface hardness, as shown in Table 2.

Table 2. Significance of the main effects and interactions calculated for surface hardness (F355A), head injury criterion (F355E), infill depth, fiber reveal, and average pile yarn weight.

\begin{tabular}{ccccccc}
\hline Effect & DF & F355A & F355E & Infill Depth & Fiber Reveal & Pile Weight \\
\hline System $(\mathrm{S})^{1}$ & 5 & $* * *$ & $* * *$ & $* * *$ & $* * *$ & $* * *$ \\
Maintenance $(\mathrm{M})^{2}$ & 1 & $* * *$ & NS 4 & $* *$ & NS & NS \\
Game $(\mathrm{G})^{3}$ & 6 & $* * *$ & $* * *$ & $* * *$ & $* * *$ & NS \\
S $\times$ M & 5 & NS & $* *$ & NS & $* *$ & NS \\
S $\times$ G & 30 & NS & NS & $*$ & $* * *$ & NS \\
M $\times \mathrm{G}$ & 6 & $* * *$ & NS & $*$ & NS & NS \\
S $\times$ M $\times$ G & 30 & NS & NS & NS & NS & NS \\
\hline
\end{tabular}

${ }^{1}$ Six 3G synthetic turf systems; ${ }^{2}$ maintenance applied (grooming, added infill) or not; ${ }^{3}$ every 20 games through 120; ${ }^{4} \mathrm{NS}$, not significant at the $p \leq 0.05$ level; ${ }^{*}$ significant at the 0.05 probability level; ${ }^{* *}$ significant at the 0.01 probability level; ${ }^{* *}$ significant at the 0.001 probability level.

Sub-plots that did not receive maintenance were 20.2 Gmax harder on average than those that were maintained (range: 6.8-30.3 Gmax). There was a significant interaction between maintenance and games, which indicated the increased variability of non-maintained surfaces in regard to surface hardness, as shown in Figure 1. Surface hardness for sub-plots maintained only deviated 3.2 Gmax compared to the overall mean, but plots that did not receive maintenance deviated by $8.2 \mathrm{Gmax}$. This comparison of deviations indicated that the consistency of a surface was greatly affected by the maintenance performed. A decrease in surface hardness between 60 and 80 games was due to higher amounts of infill due to migration to a heavy rain event during the study, as shown in Figure 1. There was not a significant interaction between the $3 G$ synthetic turf system and maintenance because of the consistent difference between maintenance and non-maintenance plots for each system, as shown in Figure 1. This lack of significance indicated that all $3 \mathrm{G}$ synthetic turf systems required the same number of grooming applications varying more than $10 \%$, and maintenance was necessary to keep surface hardness of $3 \mathrm{G}$ synthetic turf systems consistent and acceptable.

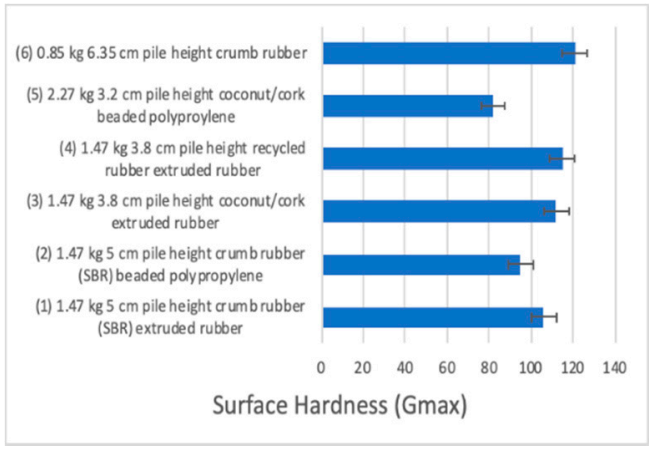

(a)

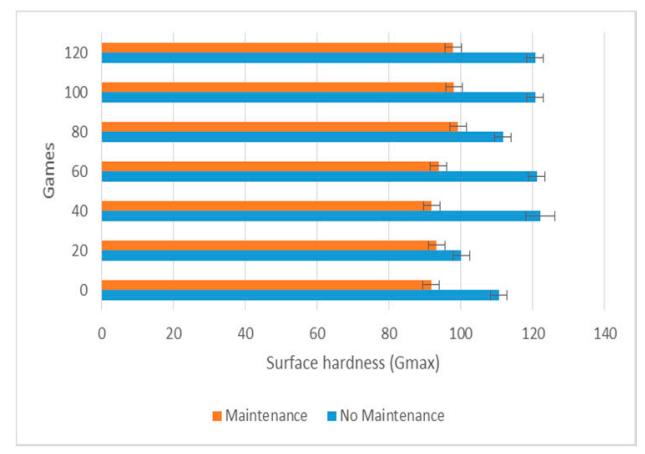

(b)

Figure 1. (a) Mean surface hardness values for the 3G synthetic turf systems over 120 games and (b) mean surface hardness was affected by the significant interaction of maintenance and games through 120 games. Surface hardness data were collected using the F355-A missile. Error bars represent standard error of the mean.

The main effect of maintenance was not significant for HIC, but there was a significant interaction between 3G synthetic turf systems and maintenance at the $1.3 \mathrm{~m}$ drop height, as shown in Figure 2. Plots that received maintenance for treatment 2, 3, and 4 had significantly lower HIC values compared to non-maintenance plots. Head injury criterion values for the other systems were 
not significantly different between maintenance and non-maintenance plots. All extruded rubber shock pads were significantly different due to maintenance level, while beaded polypropylene was not.

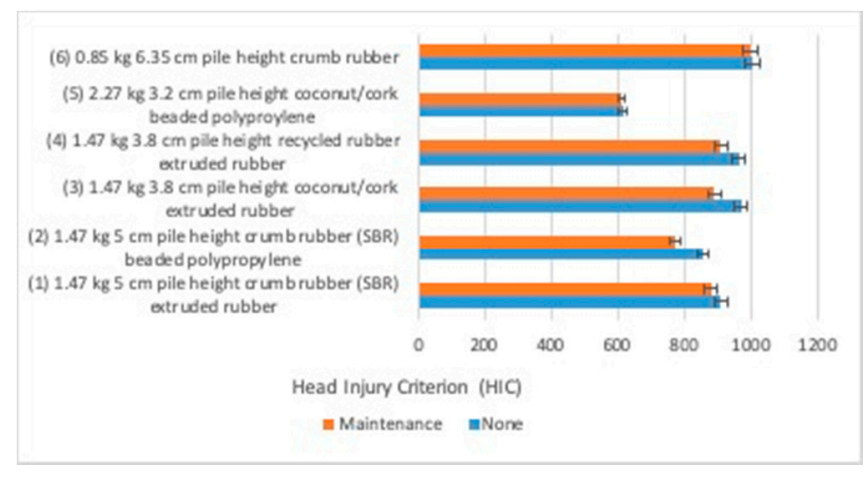

Figure 2. Head injury criterion of six different systems as affected by the interaction of 3G synthetic turf systems and maintenance from a drop height of $1.3 \mathrm{~m}$ during 2017 in Knoxville, TN, USA. Error bars represent standard error of the mean.

Plots that received maintenance, which included the addition of infill as needed, had infill levels greater than non-maintenance plots and were well within manufacturer's recommendations. The interaction of 3G synthetic turf systems and maintenance was not significant and indicated that all systems lost infill over time when not maintained. Based on the manufacturer's recommendations, infill was added to the maintenance plots whenever infill depths fell below the established minimum. A strong negative Pearson's correlation $(r=-0.92)$ was found between surface hardness and infill depth.

There was significant interaction of maintenance and traffic level for infill depth, as shown in Figure 3. Plots that received maintenance were very consistent throughout the duration of the study, but non-maintenance plots varied greatly between measurement dates. In addition to losing infill, the variability of the surface of $3 G$ synthetic turf systems greatly increased in the absence of maintenance and infill replenishment. The interaction of maintenance and traffic level was significant, as shown in Figure 3.

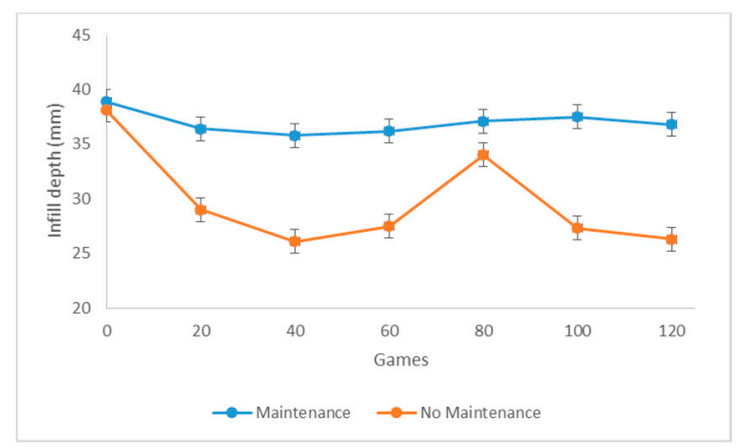

Figure 3. Average infill depth of all six systems tested affected by the significant interaction of maintenance and traffic level (games) during 2017 in Knoxville, TN, USA. Error bars represent standard error of the mean.

Infill depths for the 3G synthetic turf systems decreased when trafficked. The no maintenance plots had a spike at 80 traffic events due to a heavy rain event moving rubber that had migrated to the sides of the plots due to traffic, as shown in Figure 3. Although a portion of the infill depths contributing to the averages were consistent by conducting maintenance and replacing infill, the continual loss of infill from the non-maintenance plots caused the negative trend of the means.

There were significant main effects of the 3G synthetic turf system and game for fiber reveal, but more importantly, there were significant interactions of the $3 G$ synthetic turf system and maintenance, as well as the $3 \mathrm{G}$ synthetic turf system and traffic level (data not shown). Consistent with infill depth trends, fiber reveal differed for each system between maintenance and non- 
maintenance plots, with non-maintenance plots having greater exposed fiber. Non-maintained 3G synthetic turf had $1.1 \mathrm{~mm}$ more fiber exposed compared to maintained 3G synthetic turf. Fiber reveal varied as the turf was trafficked, which was expected considering the flexible nature of the fibers and potential for bending. It is of note that no difference in fiber wear was observed. No differences were found in amount of fiber weight. Overall, the data did not show a specific system in this study that was consistently outperforming the others.

\section{Discussion}

Based on the diversity of 3G synthetic turf systems used in this study, it was expected that there would be significant differences in surface hardness, as shown in Figure 1. Additionally, these findings correlate with previous studies $[3,4]$ that traffic level would have a significant effect on surface hardness, resulting in increased surface hardness when the system was trafficked, as shown in Figure 2. Brushing was found to be an effective tool at reducing hardness and potential compaction of the surface. The increase in surface hardness on no maintenance plots demonstrates how the maintained plots stayed closer to the starting surface hardness at game 0 . The minimal change of maintenance plots corresponds with a previous study finding decompaction through maintenance would fully reverse the effects of compaction [4]. In addition, brushing and infill maintenance can lead to a more consistent turf over time. Previous research had identified other tools that are effective at reducing surface hardness and on $3 \mathrm{G}$ fields, and these results indicate that brushing is another tool with positive impacts on a surface.

Similar to surface hardness, there was a significant main effect of the 3G synthetic turf system on HIC, as shown in Figure 2. Differences among the systems tested were attributed to the inherent capabilities of each system as they differed in combinations of shock pads, and infill type and depth. Head injury criterion from $1.3 \mathrm{~m}$ was 39.3 (HIC) less when maintenance was performed. HIC and surface hardness followed a similar established [4] trend of a softer more consistent surface when plots were maintained. Treatment 6 had the tallest fibers and greater infill in this study, suggesting greater infill at the start shows lower changes in HIC values compared with the other treatments. After installation, HIC was impacted by the amount of infill of the $3 \mathrm{G}$ synthetic turf, thus suggesting that HIC is not only impacted by the amount of infill but the inherent properties of infill as well. Extruded rubber shock pads had differences in HIC due to maintenance, where beaded polypropylene was not impacted. This suggests that the type of shock pad can have a varying effectiveness based on its construction.

Due to the nature of the $3 G$ synthetic turf systems tested, there were significant differences for infill depths as expected (data not shown). There was also a significant effect of maintenance on infill depth. Non-maintained 3G synthetic turf lost on average $6.8 \mathrm{~mm}$ (depth) more infill after 120 games than maintained turf, as shown in Figure 3. Applying maintenance provided a more consistent surface across all games. The level of infill depth throughout the study had a negative correlation with the surface hardness and HIC values. The consistent infill depth measurements in addition to the surface hardness data show, if maintained, a 3G synthetic surface could have greater field consistency and performance through a large number of games.

The greater amount of exposed fiber would be subjected to greater wear due to lack of infill providing support for the fibers. Infill depth and fiber reveal follow the same trend that applying maintenance keeps the field closer to initial installation conditions. Keeping a 3G synthetic field as close to initial installation conditions provides the optimal playing conditions and performance of the turf as seen by the results of this study. The main difference was in maintenance application and infill depth.

Although maintenance has been confirmed as important from the results of this study, additional questions that were beyond the scope of this study warrant investigation. First, how often should brushing maintenance be performed? Currently, following manufacturer's recommendations are the standard but lack verification. Second, what combination of maintenance techniques is best to maintain a 3G synthetic surface, and how does changing different components of a system impact performance? Lastly, how long does consistent maintenance increase the lifespan of 3G synthetic 
turf? The maintenance used in this study was supposed to represent a general maintenance practice; the authors are aware there are many devices and methods available. The authors are not recommending any specific maintenance practice.

\section{Conclusions}

The importance of brushing and infill maintenance on 3G synthetic turf has been confirmed by the results of this study. The action of brushing/grooming the surface redistributes infill materials and lowers surface hardness while reducing overall variability of the surface. Replacing lost infill material helps the surface perform to original installation specifications, and in this study, surface hardness and HIC $(1.3 \mathrm{~m})$ were not significantly different from game 0 to game 120 , when maintenance was performed. Infill depth on 3G synthetic turf had an inverse correlation with surface hardness and HIC. The loss of infill impacts the playability of the surface by reducing impact attenuating layers and allowing greater interaction of the player to the synthetic fibers. Overall, simple maintenance practices increased field safety while providing a consistence turf system.

Funding: This research was funded by The Toro Company and The APC was funded by The University of Tennessee.

Acknowledgments: The authors would like to thank Astroturf for the provision of the infills and 3G synthetic turf surfaces. The University of Tennessee funds the cost for this work to be published in open access.

Conflicts of Interest: The authors declare no conflict of interest.

\section{References}

1. Jastifer, J.R.; McNitt, A.S.; Mack, C.D.; Kent, R.W.; McCullough, K.A.; Coughlin, M.J.; Anderson, R.B. Synthetic turf: History, design, maintenance, and athlete safety. Sports Health 2019, 11, 84-90. doi:10.1177/1941738118793378.

2. Burillo, P.; Gallardo, L.; Felipe, J.L.; Gallardo, A.M. Mechanical assessment of artificial turf football pitches: The consequences of no quality certification. Sci. Res. Essays 2012, 7, 2457-2465.

3. Fleming, P.R.; Forrester, S.E.; McLaren, N.J. Understanding the effects of decompaction maintenance on the infill state and play performance of third-generation artificial grass pitches. Proc. Inst. Mech. Eng. Part P J. Sports Eng. Technol. 2015, 229, 169-182.

4. McLaren, N.; Fleming, P.; Forrester, S. Artificial grass: A conceptual model for degradation in performance. Procedia Eng. 2012, 34, 831-836.

5. McLeod, A.J. The Management and Maintenance of Second Generation Sand-Filled Synthetic Sports Pitches. Ph.D. Thesis, Cranfield University, Cranfield, UK, 2008.

6. Dickson, K.H.; Sorochan, J.C.; Brosnan, J.T.; Stier, J.C.; Lee, J.; Strunk, W.D. Impact of soil water content on hybrid bermudagrass athletic fields. Crop Sci. 2018, 58, 1416-1425.

7. American Society for Testing and Materials. F355-16 Standard Test Method for Impact Attenuation of Playing Surface Systems, Other Protective Sport Systems, and Materials Used for Athletics, Recreation and Play; ASTM International: West Conshohocken, PA, USA, 2016.

8. American Society for Testing and Materials. F1292-17 Standard Specification for Impact Attenuation of Surfacing Materials within the Use of Zone of Playground Equipment; ASTM International, West Conshohocken, PA, USA, 2017; doi:10.1520/F1292-17.

(C) 2020 by the authors. Licensee MDPI, Basel, Switzerland. This article is an open access article distributed under the terms and conditions of the Creative Commons Attribution (CC BY) license (http://creativecommons.org/licenses/by/4.0/). 